IJBPAS, December, 2020, 9(12): 3333-3349

ISSN: 2277-4998

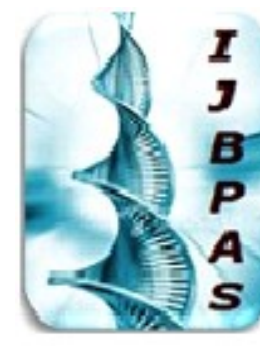

International Journal of Biology, Pharmacy

and Allied Sciences (IJBPAS)

'A B ridge Betuen Caboratory and Q Qndor'

Www.iibpas,com

\title{
NEUROPROTECTIVE EFFECT OF ALPHA LIPOIC ACID ON ROTENONE INDUCED NEURODEGENERATION IN ZEBRA FISH
}

\section{MOHANA J AND PRASAD N*}

DMPK \& Clinical Pharmacology Division, Department of Pharmacology, University College of Pharmaceutical Sciences, Kakatiya University, Warangal-506 009, T.S. India

*Corresponding Author: Prasad N: E Mail: prasadneerati@gmail.com; Cell: 91-9494812120

Received 11 ${ }^{\text {th }}$ April 2020; Revised $2^{\text {nd }}$ May 2020; Accepted $26^{\text {th }}$ May 2020; Available online $1^{\text {st }}$ Dec. 2020

\section{https://doi.org/10.31032/IJBPAS/2020/9.12.5271}

ABSTRACT
Oxidative stress mediated injury is one of the major reasons of occurrence of neurodegeneration which leads to Parkinson's disease and Alzeimer's disease. Alpha-lipoic acid (ALA) is a vitaminlike chemical and a potent antioxidant with the potential use as medicine. Till now there are no reports with ALA for the neuroprotective action with rotenone (ROT) challenge by using Zebra fish, so this work has been done to explore the neuroprotective activity. Adult male Zebra fish ( $\mathrm{n}=$ 12) were used and simultaneously exposed allowed to swim to ROT $50 \mu \mathrm{g} / \mathrm{ml}$ and ALA $500 \mu \mathrm{g} / \mathrm{ml}$ in a glass water tank of $2 \mathrm{~L}$ for 14 days, and the methods like biochemical parameters from brain tissue, behavioral studies and histopathology studies were done to prove neuroprtection. ROT produced marked decrease in the Zebra fish swimming behavior and induced the locomotor and cognitive impairment significantly. ROT +ALA combined treatment significantly improved the swimming behavior and attenuated the locomotor, cognitive impairments induced by ROT. The results were confirmed by the histopathological findings also. The results concludes that the ALA was effective against the toxicity induced by ROT in Zebra fish as well as confirms the significance of this model to explore possible therapeutic approaches with ALA on cognitive impairments and movement disorders and further studies are needed to explore the therapeutic use of ALA in Parkinson's and Alzheimer's diseases.

Key words: Alpha-lipoic acid, Zebra fish, Rotenone, Neurodegenerative disorders 


\section{INRODUCTION}

This study was focused to explore weather alpha lipoic acid shows action on both Parkinson's and Alzheimer's diseases. The animal model used is zebra fish it is a best model when compared to other animal models, have $95 \%$ homology to humans. Zebra fish share $84 \%$ of genes associated with human dementia including similar to APP, MAPT, PSEN1 and PSEN2. Zebra fish have forebrain, midbrain, hind brain and their peripheral nervous system has comparable sensory and motor capabilities. Its blood brain barrier is functional in three days after fertilization, which allows for pharmacological screening similar to that used with higher vertebrates and has easily observable phenotypes that are comparable to those seen in humans. Neurodegeneration is a distinctive attribute of most defenseless and incurable diseases that are expeditiously increasing in prevalence among hundreds of neurodegenerative diseases so far paid attention towards only Alzheimer's, Parkinson's, amylotropic lateral sclerosis and Huntington's disease. The term neurodegeneration derived as neuro refers to nerve and degeneration refers to loss of structure or function of neuron [1]. The zebra fish (Danio rerio) is progressively exploit a powerful animal model in neuropharmacology research we discuss Alzheimer's and Parkinson's disease these are devastating neurodegenerative disease with no effective treatment and usually diagnosed only on late stages amyloid $A \beta$ accumulation and exacerbated tau phosphorylation are molecular hallmark for Alzheimer's disease and decrease of dompaminergic neurons and parkin, synuclein gene mutation are responsible for Parkinson's disease [2]. Oxidative stress occurs when the production of free radicals or their products are in excess of antioxidant defense mechanisms. It is a major factor of the cytopathology of many diseases including neurodegenerative disorders and their models. The generation of reactive oxygen species during early stage protein aggregation is a common fundamental molecular mechanism underlying their pathogenesis and other contributors are metal-iron associated Fenton reactions, lipid peroxidation and nitric oxide induced protein nitrosylation [3].

Generation of excessive nitric oxide and reactive oxygen species can mediate protein misfolding in the absence of genetic predisposition. Among the various free radicals generated in the living organism, hydroxyl radical and peroxynitrite are the 
most potent and can damage cells via nonselective oxidation of proteins, lipids, fatty acids and nucleic acid [4]. They are formed between hydrogen peroxide and reduced transition metals. Hydrogen peroxide is later converted to hydroxyl radicals by the addition of Fe (II) by Fenton's reaction, one of the fundamental mechanisms neurodegenerative processes. The accumulation and precipitation of proteins may be serious damage by oxidative stress, and may, in turn, cause more oxidative damage by interfering with the function of the proteasome, that increases levels of oxidative stress not only to proteins but also to other biomolecules [5]. Proteins are initial targets of reactive oxygen species, and protein radicals generated by reactive oxygen species can oxidize reduced glutathione, which triggers dysregulation of calcium homeostasis, reactive astrogliosis and other changes observed in neuronal dysfunction. Superoxide is suggested to be the major reactive oxidative stress regulating autophagy. Cells which fail to reduce oxidative imbalance (stress) enter apoptosis with rapid cell death, while those with compensatory response to reactive oxygen species may show long-term survival [6]. Free radical oxygen chemistry plays an important pathogenic role in all these conditions, though it is as yet Huntington disease determined what types of oxidative damage occur early in the pathogenic cascade and which ones are secondary manifestation of dying neurons. Heat shock proteins have been shown to protect against oxidative stress [7]. Alterations in metal homeostasis leads to increased production of free radicals, suggests a direct cause-effect relationship between disruption in metal homeostasis and the increased oxidative damage. In addition to the generation of oxygen and hydrogen peroxide, the availability of redox-active $\mathrm{Fe}$ is a major determinant of reactive oxygen species mediated cellular damage. Elevated levels of redox-active Fe, derived from degenerating mitochondria, accumulate in the normal aging brain and in several neurodegenerative disorders [8]. Conditions such as neuroferritinopathy and Friedreich ataxia are associated with mutations in genes that encode proteins involved in iron metabolism, inducing oxidative species and cell death the brain ages, iron accumulates in regions that are affected by Alzheimer's disease, and Parkinson's disease, and dopamine complexes of iron are important in the pathogenesis of Parkinson's disease [9].

Common pathogenic mechanisms underlying many neurodegenerative disorders includes; 
Abnormal protein dynamics with misfolding, defective degradation, proteosomal dysfunction and aggregation; often with molecular chaperons. Oxidative stress and formation of free radicals/reactive oxygen species (ROS). Impaired bioenergitics, mitochondrial dysfunction and DNA damage. Fragmentation neuronal Golgi apparatus. Disruption of cellular/axonal transport ( $4 \& 5$ may be regarded as secondary effects). Dysfunction of neurotropins, neuroinflammatory / neuroimmune process are mechanisms are interrelated in complex vicious circles finally leading to cell dysfunction and death [10]. Abnormal interactions between proteins that result in aberrant intra and extracellular deposition of self-aggregating misfolded proteins with formation of high-ordered insoluble fibrils are pathological hallmarks of many neurodegenerative diseases [11]. Abnormal protein-protein interactions and/or the lesions that result from them trigger vicious circles leading to dysfunction and death of neuronal and glial cells [12]. The neurodegenerative process and the mutation in the genes encoding protein constituents may be associated with a variety of clinicopathological phenotypes, with identical phenotypes may be related to different genetic defects. Abnormal interaction between normal, highly soluble brain proteins alters their conformation, and misfolding gradually converts them into insoluble polymers with the aggregates adopting either highly ordered or disordered forms. Since deposits of natively unfolded proteins aggregated into defined fibrillar structures will display the properties of amyloid, these disorders are grouped together as brain amyloidosis [13]. A link between the formation of protein aggregates and neuronal dysfunction is due to be a result of the toxic action of substances produced during early phases, i.e. soluble oligomers and protofibrillar derivatives of misfolded proteins [14]. The 'toxic oligomer' hypothesis is by finding that a single-domain antibody can recognize a common conformational epitope that is displayed by several disease-associated proteins, including amyloid, synuclein protein, prions and polyglutamine peptides. Soluble amyloid oligomers are increased in Alzheimer's disease (AD) in both brain tissue and plasma [15].

Proteins are a heterogeneous system of different conformers which, due to their flexibility, are in a dynamic state between different conformational substrates maintained by synthesis and degradation [16]. The process that converts newly 
synthesized proteins to physiologically functional molecules is controlled by molecular chaperones that prevent inappropriate interaction between non-native polypeptides and promote the refolding of proteins that have become misfolded as a result of cellular stress [17]. Protein aggregation occurs in vivo as a result of misfolding leading to a structural change of a normal, functional protein, leads to the formation of protein aggregates into various supramolecular organizations Aberrant proteins, the result of production errors, inherited amino acid substitutions, often cannot fold correctly and will be trapped in misfolded conformations. The pathogenic pathways involve membrane permeabilization through a channel mechanism known as hydrophobic interaction of prefibrillary oligomers with various cellular targets [18]. To get rid of misfolded proteins, the living cell contains a large number of intracellular proteases, combined with the chaperones consist of cellular protein quality-control systems in the endoplasmic reticulum. Quality control against misfolded proteins is the cytosole in a network for cell survival and endoplasmic reticulum protein quality control in neurodegenerative disorders [19]. Many proteins associated with neurodegenerative disorders are intrinsically disordered under physiological conditions [20]. Progressive intracellular protein accumulation can result from various pathological processes; like abnormal synthesis and folding, abnormal interaction with other proteins, overproduction of protein constituents, impaired degradation and turnover, altered post-translational modifications of newly synthesized proteins, protein oxidation, nucleic acid-induced structural conversions, abnormal proteolytic cleavage, improper expression or altered gene splicing, insufficient molecular chaperone activity and impaired intracellular transport of proteins [21]. Due to the central role of these phenomena in cell biology, protein misfolding and aberrant disorder-to-order conformational transitions in protein structure are associated with a large number of neurodegenerative disorders. Causes are genetic deficits producing a single amino acid substantiation or expansion of a repeating amino acid tract, as occurs in most neurodegenerative disorders that occur sporadically, other factors may induce the pathogenic cascade [22]. Alpha Lipoic acid (ALA) is a potent antioxidant, it may produce neuroprotection, so this study was done, in Zebra fish rotenone (ROT) induced model of neurodegeneneration. 


\section{MATERIALS AND METHODS}

Materials Rotenone (Sigma Aldrich), $\alpha$-lipoic acid (Sigma Aldrich), Thio Barbituric Acid (TBA) (Himedia), 5,5'-Dithio, bis(2-nitro benzoic acid) (Himedia), Folin and Wu's Alkaline copper sulphate reagent (Sigma Aldrich), Folin-Ciocalteau's Phenol reagent (Sigma Aldrich), Sodium Nitrite (Himedia), Bovine Serum Albumin (BSA) (Sigma Aldrich), Sodium Dodecyl Sulphate (SDS) (Himedia), Pyridine (Sigma Aldrich), nButanol (Sigma Aldrich), Sodium dihydrogen phosphate (Himedia), Disodium hydrogen phosphate (Himedia), Tri Chloro Acetic acid (TCA) (Sigma Aldrich), Reduced Glutathione (Sigma Aldrich), Tetra Ethoxy Propane (TEP) (Himedia), Sulfanilamide (Himedia), 2,3,5- Triphenyl tetrazolium chloride (Sigma Aldrich), N- (1- Naphthyl) Ethylene Diamine Dihydro chloride (NEDD) (Himedia), Ethylene Diamine Tetra Acetic acid (EDTA) (Himedia), 5-Sulfosalicylic acid (Himedia), Sodium CMC (Himedia), Glacial Acetic Acid (Himedia), Tris Hydrochloride (Sigma Aldrich).

\section{Animals}

Adult female Zebra fish weighing $0.3 \mathrm{~g}-5 \mathrm{~g}$ were procured from Center for Cellular and Molecular Biology (CCMB) Hyderabad. Animals were housed in glass aquarium at temperature $(28 \pm 1)$. They were fed with PL-
500 and micro sized fish feed, in laboratory drinking water. They were left to accommodate for one week before the experiment. The experimental protocol is ethically approved by Institutional Animal Ethical

Committee

No.IAEC/21/UCPSc//KU/19, Kakatiya University, Warangal.

\section{Acute toxicity study of ROT and ALA:}

After conducting pilot studies, the acute toxicity study of rotenone at different doses like $1 \mu \mathrm{g} / \mathrm{ml}, 5 \mu \mathrm{g} / \mathrm{ml}, 10 \mu \mathrm{g} / \mathrm{ml}, 50 \mu \mathrm{g} / \mathrm{ml}$, $100 \mu \mathrm{g} / \mathrm{ml}$ and with alpha lipoic acid at the dose levels of $5 \mu \mathrm{g} / \mathrm{ml}, 50 \mu \mathrm{g} / \mathrm{ml}, 100 \mu \mathrm{g} / \mathrm{ml}$, $500 \mu \mathrm{g} / \mathrm{ml}$ and $1000 \mu \mathrm{g} / \mathrm{ml}$ were selected to prepare the swim tank of the Zebra fish and allowed to swim freely to check the survival and death number of fishes with ROT and ALA, then after the effective dose is selected for the study.

\section{Induction of neurodegeneration by ROT:}

The concentration of ROT is selected based on pilot study. The stock solution of ROT was prepared at concentration of $50 \mu \mathrm{g}$ is added in $0.5 \mathrm{ml}$ of DMSO $1 \%$ and $0.5 \mathrm{ml}$ of PEG300 $10 \%$ made up to $1 \mathrm{ml}$, then this is added to make up to $2 \mathrm{~L}$ of normal water at room temperature for about 21 days, is the induction duration. Experimental procedure, the Zebra fish were randomly divided into 4 groups $(n=12)$, and were fed with food (PL- 
500 taken from CCMB) twice daily. After induction of 21 days, the $21^{\text {st }}$ day is considered to be day 0 , from day 1 the treatment is given for four groups with $500 \mu \mathrm{g} / \mathrm{ml}$ of ALA. $1^{\text {st }}$ group is Normal group where DMSO $(0.1 \%)$ and PEG300 $(10 \%)$ of $1 \mathrm{ml}$ is mixed in $2 \mathrm{~L}$ of water and fishes are allowed to swim freely, $2^{\text {nd }}$ group ROT induced group where the drug is mixed in $2 \mathrm{~L}$ of water in $50 \mu \mathrm{g} / \mathrm{ml}$ of DMSO and PEG300 $(10 \%)$ and allowed for swim freely, $3^{\text {rd }}$ group ROT + ALA $500 \mu \mathrm{g} / \mathrm{ml}$ is mixed in $2 \mathrm{~L}$ of water and allowed to swim freely, $4^{\text {th }}$ group ALA alone $500 \mu \mathrm{g} / \mathrm{ml}$ is mixed in $2 \mathrm{~L}$ of water under room temperature and allowed to swim freely. Days 1, 7 and 14 the behavioral studies are carried out and histopathology studies are done by taking brain samples. On $14^{\text {th }}$ day the fishes were sacrificed, and brains were collected for biochemical estimations.

\section{METHODS}

Methods for the estimation of Biochemical Parameters:

Preparation of Tissue Homogenate: - All the animals were sacrificed on the $22^{\text {nd }}$ day after the experimentation. The brain tissues were quickly isolated and the tissue homogenate $(10 \%, \mathrm{w} / \mathrm{v})$ was prepared with 0.1 M Tris- $\mathrm{HCl}$ buffer ( $\mathrm{pH}$ 7.4), for estimation of reduced glutathione, nitric oxide content, lipid peroxidation and total protein content. Extraction procedure from tissue homogenate/aliquot $1 \mathrm{ml}$ supernatant was precipitated with $1 \mathrm{ml}$ of sulfosalicylic acid and cold digested at $4^{\circ} \mathrm{c}$ for $1 \mathrm{hr}$ and cold centrifuged at $4^{\circ} \mathrm{C}$ at $1200 \times \mathrm{g}$ for $15 \mathrm{mins}$ then the supernatant was collected and used for assay [23].

Procedure for estimation of GSH in tissue: Homogenate Tissue extract was prepared by the procedure mentioned above and $0.2 \mathrm{ml}$ of tissue extract was taken and $2.3 \mathrm{ml}$ of $0.1 \mathrm{M}$ Phosphate buffer ( $\mathrm{pH}$ 7.6) and $0.5 \mathrm{ml}$ of $1 \mathrm{mM}$ DTNB were added, incubated for $5 \mathrm{mins}$ at room temperature. The absorbance of yellow color produced was observed at $412 \mathrm{~nm}$ using Systronics, Spectrophotometer [24].

\section{Procedure for estimation of Nitric Oxide} content in tissue homogenate: A modified method of Nitric Oxide content estimation described by Green et al., 1982 was used. 0.2 $\mathrm{ml}$ of tissue homogenate was taken and the volume was adjusted to $1.5 \mathrm{ml}$ using $100 \mathrm{mM}$ Tris $\mathrm{HCl}$ buffer ( $\mathrm{pH}$ 7.4). To this, $1.5 \mathrm{ml}$ of Griess reagent was added and incubated for $10 \mathrm{mins}$ at room temperature. Absorbance was observed at 546nm using Systronics, spectrophotometer [25].

Lipid Peroxidation Assay: Procedure for preparation of sample MDA levels in tissue homogenate were measured by the method 
developed by Ohkwa et al., 1979. 0.2ml of tissue homogenate was taken and to this 0.2 $\mathrm{ml}$ of $9.1 \%$ SDS, $1.5 \mathrm{ml}$ of $20 \%$ acetic acid and $1.5 \mathrm{ml}$ of $0.9 \%$ aqueous solution of TBA were added. The mixture was made up to $5 \mathrm{ml}$ with distilled water and then heated in an oil bath at $95^{\circ} \mathrm{c}$ for $1 \mathrm{hr}$. Then it was cooled and $5 \mathrm{ml}$ of mixture of n-butanol and pyridine $(15: 1 v / v)$ was added and shaken vigorously. Then the mixture was centrifuged at 4000rpm for $10 \mathrm{mins}$ and the organic layer was separated and absorbance was measured at 532nm. The tissue MDA levels were measured from the standard curve and expressed as $\mathrm{nM} / \mathrm{g}$ tissue [26].

Total Protein Assay: Procedure for the estimation of Total Protein levels in the tissue homogenate Estimation of total protein levels in the brain homogenate was done by the method established by Lowry et al., 1951. $0.2 \mathrm{ml}$ of brain homogenate was taken in test tube and it was added with $2 \mathrm{ml}$ of Copper sulphate reagent and incubated for $10 \mathrm{mins}$ at room temperature. The solution was added with $0.2 \mathrm{ml}$ of Folin Ciocalteau reagent and again incubated for $30 \mathrm{mins}$ at room temperature. After the incubation, it was added with $5 \mathrm{ml}$ of $100 \mathrm{mM}$ Tris $\mathrm{HCl}$ buffer containing $\mathrm{pH}$ 7.4. Then, absorbance was measured at $660 \mathrm{~nm}$ using Systronics Visible Spectrophotometer [27].

\section{Methods for determining behavioral parameters}

T-maze test: The apparatus was constructed of glass and consist of three identical arms. Starting arm: is the fish starting to explore. Green arm: The fish is going to be reward with food. Red arm: The fish is going to be reward with punishment. Each arm was $35 \mathrm{~cm} \times 12 \mathrm{~cm} \times 75 \mathrm{~cm} \quad($ width $\times$ height $\times$ length $)$. The maze is filled up to $10 \mathrm{~cm}$ height with water. Fish allowed adopting for $5 \mathrm{~min}$ when introduced to system. Time for fish to find the container was recorded. After finding the container fish are allowed to swim for $2 \mathrm{~min}$ before being caught and tested again and the fishes were tested three times per day [28].

Place preference test: Fish were tested in a two chambered place preference box. The test apparatus was $50 \times 20 \times 22 \mathrm{~cm}$ and was filled up to $20 \mathrm{~cm}$ from bottom. The apparatus was divided into two equal halves with perforated walls that allow movement. The temperature of the apparatus is maintained at $28^{\circ} \mathrm{C}$ and the $\mathrm{pH}$ of 7.3 was controlled by sodium bicarbonate. The fish was allowed to practice the movement the presence of two compartments in apparatus. Each fish was placed in the alternative compartment of place preference box and allowed to swim freely from one compartment to other. The number of entries 
into each compartments and time spent in each compartment were recorded [29].

Motor ability Test: Dysfunction of locomotor activity is a clinical syndrome for Parkinson's disease. The locomotor activity of zebra fish was assessed in a $2 \mathrm{~L}$ tank filled with normal behavior of to swim back and forth along the length of the tank. The simple observation was used to determine the locomotor activity of Zebra fish. The vertical lines were drawn on the tank at equal distances dividing the tank into four zones. Locomotor activity was measured for $5 \mathrm{~min}$ by counting number of lines that each Zebra fish crossed. Therefore the total distance that the Zebra fish traveled was in directly proportional to total number of lines that the fish crossed. The locomotor activity was calculated by the total number of lines that the Zebra fish crossed, divided by time and expressed in the number of lines crossed lines $/ 5 \min [30]$.

\section{HISTOPATHOLOGY}

On $1^{\text {st }}$ and $14^{\text {th }}$ day, the Zebra fish brain tissue is isolated grouped as Normal, ROT induced, ROT + ALA, ALA alone groups and kept in $10 \%$ formaldehyde and a code was assigned. The tissue passage stages, including dehydration and clearing of the nerve, were performed automatically, and then paraffin fixed blocks were prepared.
From each tissue, $5-\mu$ slices were prepared by microtome and stained with hematoxylin and eosin (H\&E). The morphology was evaluated qualitatively by light microscopic with 100x magnification by the pathologist blinded to animal group and drug used. Neurodegeneration was evaluated by apoptosis and cell damage.

\section{Statistical Analysis}

Data were expressed as means \pm S.E.M. Differences normal group vs other groups were determined either by one-way ANOVA followed by Bonferroni's test for Biochemical estimations. The result analyzed for Behavioral parameters assessed one-way ANOVA between the control group vs other groups followed by dunnets test. A value of $\mathrm{P}$ $<0.05$ was considered statistically. Statistical analysis was performed using the $G R A P H$ PAD PRISM 8.4 software.

\section{RESULTS}

From the acute toxicity study the effective dose of rotenone and alpha lipoic acid found to be $50 \mu \mathrm{g} / \mathrm{ml}$ and $500 \mu \mathrm{g} / \mathrm{ml}$ respectively (Table 1).

Biochemical parameters were explaining ROT treated group inducing oxidative stress where as the ROT+ALA treated groups were showing antioxidant potential. From $1^{\text {st }}$ to $14^{\text {th }}$ day the antioxidant potential is progressive and reduced glutathione levels of 
ROT induced from $0.0977 \pm 0,027$ to

$0.915 \pm 0.060$ (Figure 1A), nitric oxide levels from $0.528 \pm 0,054$ to $0.107 \pm 0.011$ (Figure

1B), lipid peroxidation levels from $0,836 \pm 0,034$ to $0.157 \pm 0,013$ (Figure 1C), and total protein content levels from $0.563 \pm 0.012$ to $0.206 \pm 0.042$ (Figure 1D) respectively and all the results were statistically significant.

ROT induced neurodegeneration effectively and cognitive impairment was progressive up to 14 days of the study in Zebra fish.
Cognitive impairment was progressively improved on $14^{\text {th }}$ day the reduced glutathione levels of ROT induced from $94.60 \pm 6.0$ to ROT +ALA treated $49.5 \pm 4.52$ (Figure 2A), place preference test $96.6 \pm 3.3$ to $15.5 \pm 1.8$ (Figure 2B), and Motor ability test $626 \pm 43$ to $1132 \pm 70$ (Fig 2C) respectively and the all the results were significant.

Histopathalogical studies explaining the progressive repair in the Zebra fish brain cellular damage from day $1^{\text {st }}$ to $14^{\text {th }}$ day (Figure 3 A-D).

Table 1: Represents the response to different doses of ROT and ALA. ROT-Rotenone, ALA-Alpha Lipoic acid, S-Survival Number, D-Death Number

\begin{tabular}{|c|c|l|r|r|r|r|c|}
\hline SI. No. & Groups & \multicolumn{6}{l|}{ Dose ranges in experimental protocol (Zebra fish n=12) } \\
\hline \multirow{2}{*}{1.} & ROT & Dose & $1 \mu \mathrm{g} / \mathrm{ml}$ & $5 \mu \mathrm{g} / \mathrm{ml}$ & $10 \mu \mathrm{g} / \mathrm{ml}$ & $50 \mu \mathrm{g} / \mathrm{ml}$ & $100 \mu \mathrm{g} / \mathrm{ml}$ \\
\cline { 3 - 8 } & & S / D & $12 / 0$ & $12 / 0$ & $12 / 0$ & $12 / 0$ & $0 / 12$ \\
\hline \multirow{2}{*}{2.} & ALA & Dose & $5 \mu \mathrm{g} / \mathrm{ml}$ & $50 \mu \mathrm{g} / \mathrm{ml}$ & $100 \mu \mathrm{g} / \mathrm{ml}$ & $500 \mu \mathrm{g} / \mathrm{ml}$ & $1000 \mu \mathrm{g} / \mathrm{ml}$ \\
\cline { 3 - 8 } & & S / D & $12 / 0$ & $12 / 0$ & $12 / 0$ & $12 / 0$ & $0 / 12$ \\
\hline
\end{tabular}

\section{DISCUSSION}

In the initial stages of Alzheimer's disease, $\mathrm{A} \beta$ deposition and phosphomay represent compensatory responses to ensure that neurons may not succumb to oxidative damage. Oxidative stress induces macroautophagy of $A \beta$ protein and ensuing apoptosis. Mutant APP and its derivates are involved in the generation of free radicals in mitochondria and cause mitochondrial oxidative damage, linking $\mathrm{A}$, generation of free radicals and oxidative damage in the pathogenesis of Alzheimer's disease [31].
Increase of iron in the substantial nigra with a shift of Fe (II): Fe (III) of 2:1 as compared to $1: 2$ in controls and aggregation of dopamine can promote synthesis with accompanying increased generation of reactive metabolites, leading to degeneration [32]. In this study ROT is taken as inducing neurodegeneration in Zebra fish and ALA for the treatment to attenuate the neurodegeneration as it is potent antioxidant [33]. We investigated whether it shows action on both Parkinson's and Alzheimer's diseases. Here the animal model used is zebra fish it is 
a best model when compared to other animal models and is easy to breed, mature quickly, and have $95 \%$ homology to humans. Zebra fish share $84 \%$ of genes associated with human dementia including similar to APP MAPT PSEN1 and PSEN2 [34]. Zebra fish have forebrain, midbrain, hind brain and their peripheral nervous system has comparable sensory and motor capabilities [35]. Zebra fish blood brain barrier is functional in three days after fertilization, which allows for pharmaceutical screening similar to that used with higher vertebrates ands have easily observable phenotypes that are comparable to those seen in humans [36].

Neurodegeneration is a feature of many vulnerable, incurable diseases that are rapidly rising in prevalence such as Parkinson's and Alzheimer's diseases. There is an essential need to develop new and more effective therapeutic strategies to combat this disastrous disease. There are many drugs with potential effect, but it has many side effects, so it has become necessary to introduce novel therapeutics to treat various neurodegenerative diseases. Present study was aimed to explore the neuroprotective effect of ALA on ROT induced neurodegeneration. ALA acts as antioxidant and reduces the reactive oxygen species finally reduces the neurodegeneration. In the evaluation of the behavioral parameters such as T-Maze test Place preference test for Alzheimer's and Motor ability for Parkinson's disease the biochemical studies such as reduced glutathione estimation, lipid peroxidation, nitric oxide assay, total protein count. The other is Histopathological studies. In the evaluation of behavioral effects of $\mathrm{T}$ Maze test showed moderate changes of cognition, Place Preference test conformed that cognitive effects has increased by the Motor ability test the locomotor effects have been evaluated and conformed the movement has been moderately increased. The glutathione levels have increased moderately nitric oxide levels has become near to normal Total protein count has been become normal in treated groups compare to induced group. It has moderate effect on lipid peroxidation and histopathological studies. ALA has not only the anti-oxidant by relieving oxidative stress but also proved that it has antiinflammatory effects so that the moderate effects has been observed in treatment of Alzheimer and Parkinson's disease. From the histopathological studies it was evidence that the alpha lipoic acid has the neuroprotective effect against the neurodegeneration. 

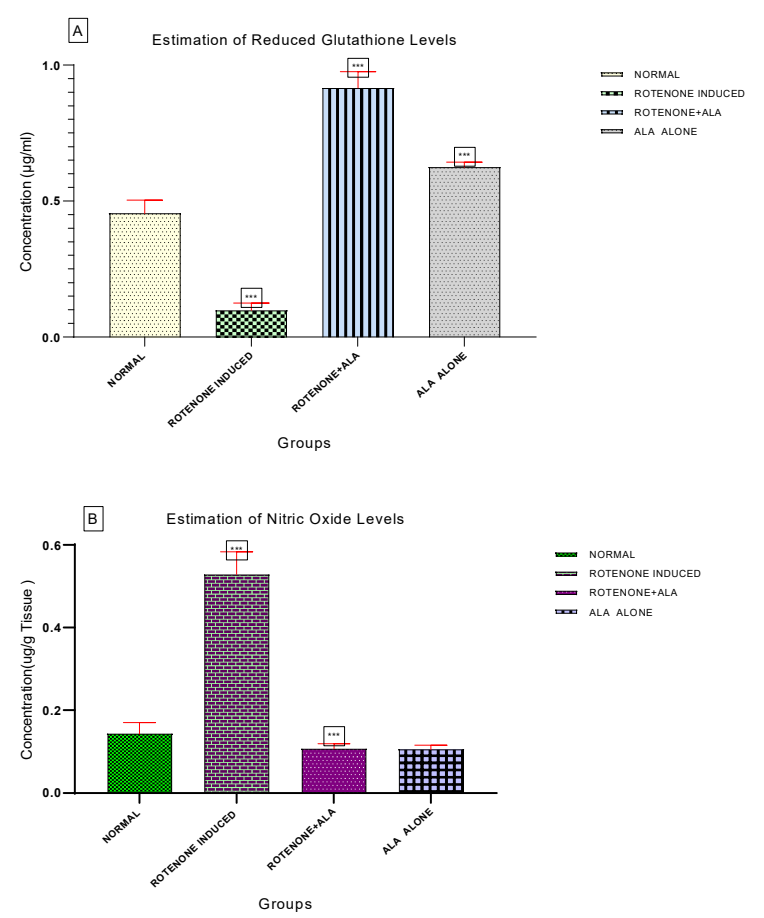

- NORMAL

- ROTENONEAACA

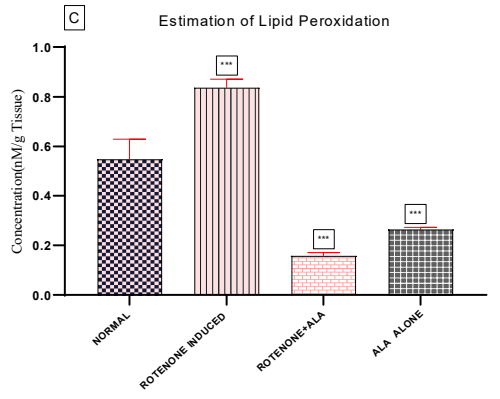

- NoRMAL
m. ROTENNNE MOUCEO

- ROTENONEALLA

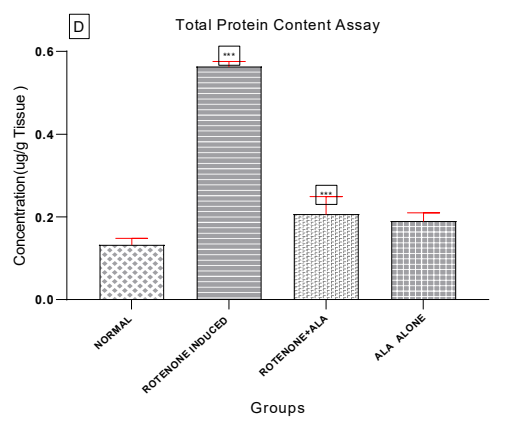

- nовмаг

- ROTENONE NOUCE

$=$ ROTENONEAALA
$=$ ALA ALONE

Assay. All the results expressed in Mean \pm SEM and $* \mathbf{p}<0.05, * * p<0.01$ and $* * * p, 0.001$ 

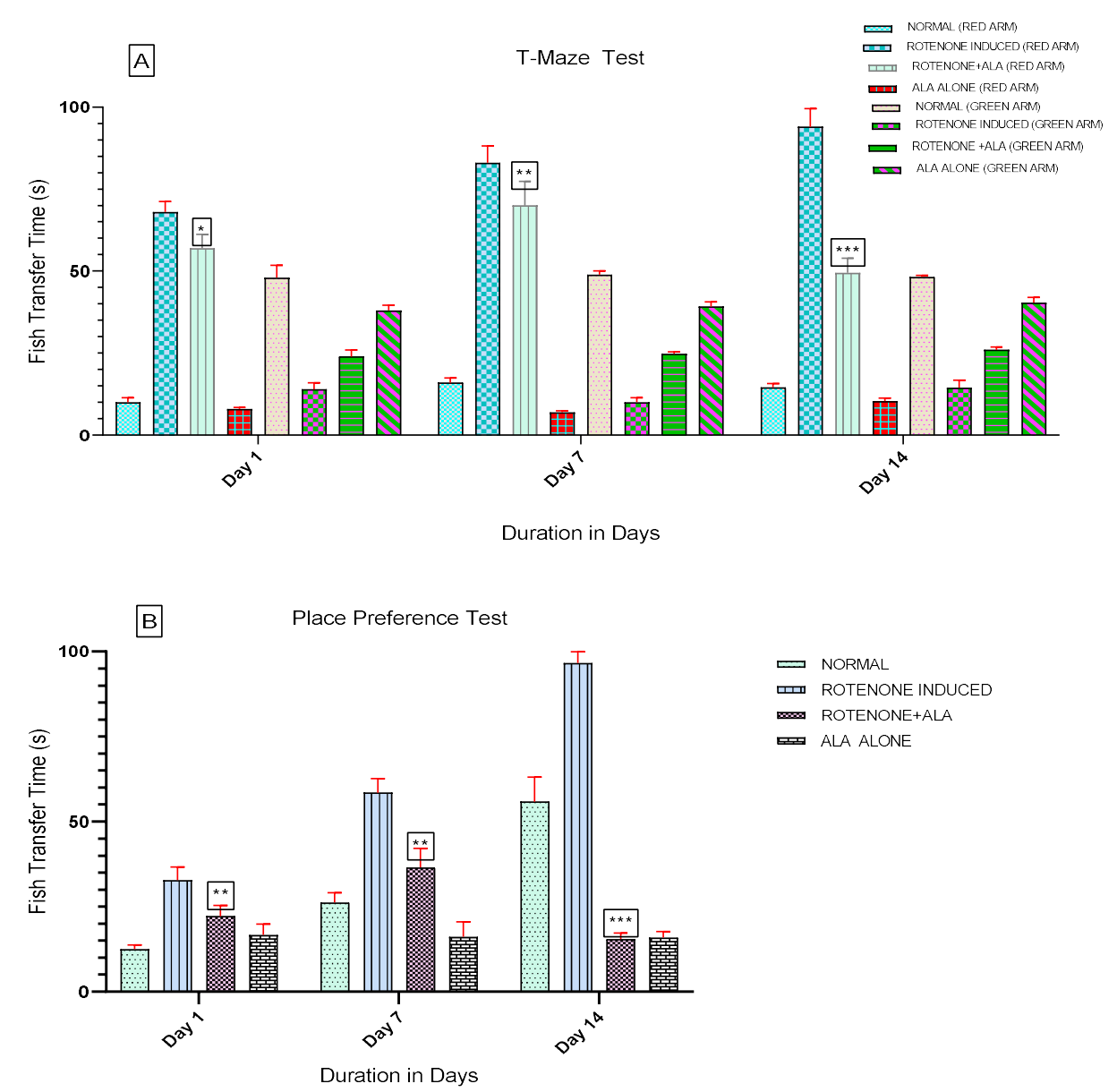

$$
\begin{array}{ll}
= & \text { NORMAL } \\
\text { mOTENONE INDUCED } \\
\text { ROTENONE+ALA } \\
\text { ALA ALONE }
\end{array}
$$

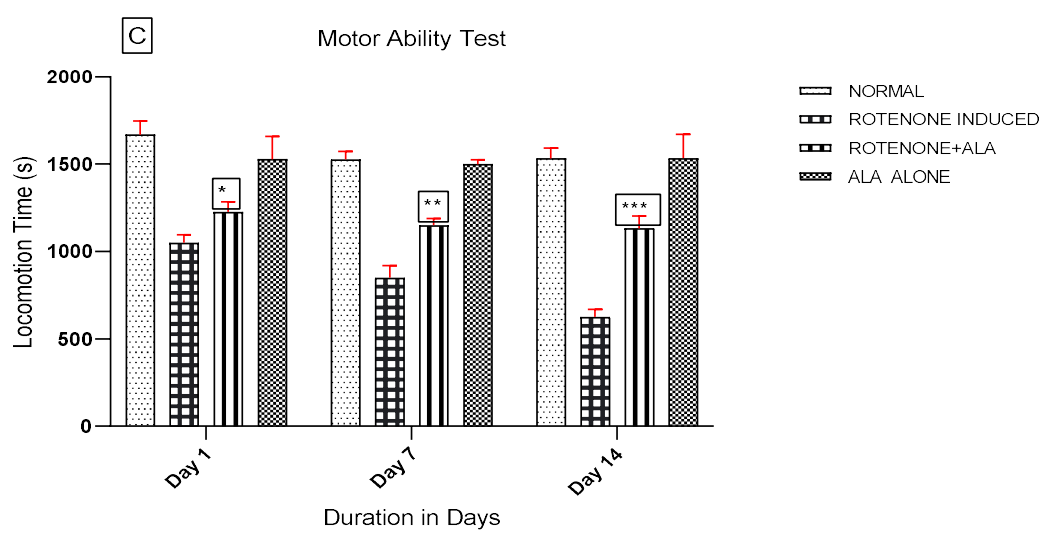

Figure 2: A) T-Maze Test, B) Place preference C) Motor Ability Test. All the results expressed in Mean \pm SEM and $* \mathbf{p}<0.05, * * \mathbf{p}<0.01$ and $* * * \mathbf{p}, 0.001$ 


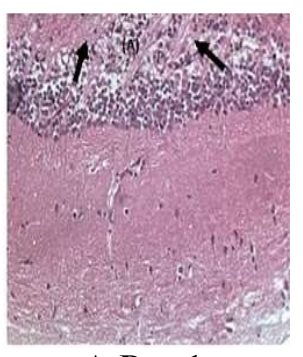

A-Day 1

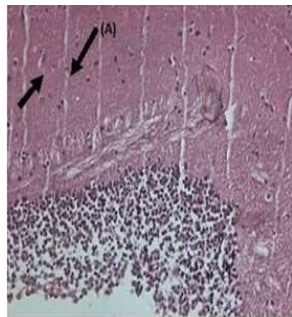

A-Day 14

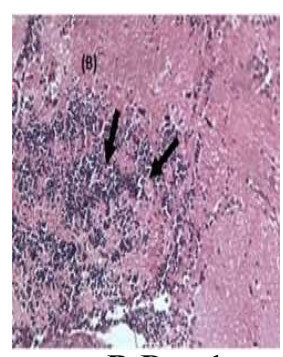

B-Day 1

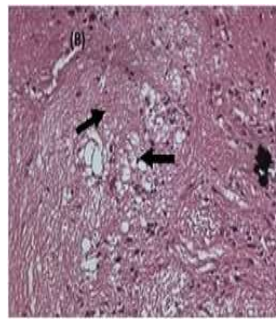

B-Day 14

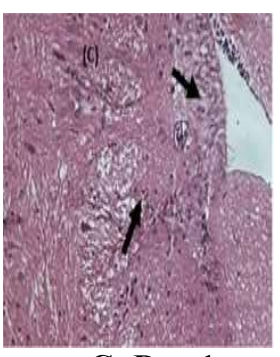

C -Day 1

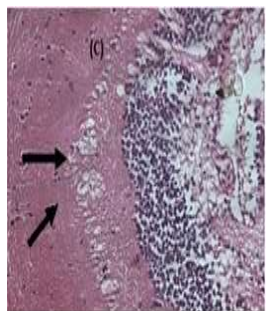

C -Day 14

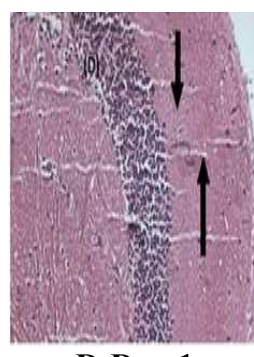

D-Day 1

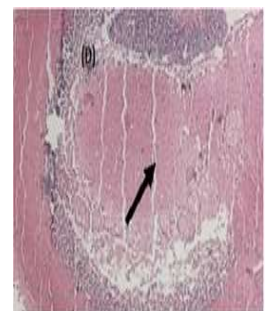

D-Day 14

Figure 3: Histopathology of Zebra fish brain (100 x) of (A) Normal, (B) Rotenone induced, (C) Rotenone+ Alpha lipoic acid, (D) Alpha lipoic acid alone groups are taken on the $1^{\text {st }}$ day and $14^{\text {th }}$ day of the treatment

\section{CONCLUSION}

ALA attenuates the neurodegeneration induced by the ROT in Zebra fish by ameliorating the behavioral biochemical and histopathological signs and symptoms. This attenuation may be attributed due to antioxidant activity ALA can treat not only the Parkinson's disease but also Alzheimer's disease. Further studies are needed to prove the therapeutic benefits in patients.

\section{ACKNOWLEDGMENT}

The authors are thankful to CCMB, Hyderabad for free supply of Zebra fish and also thankful to University College of Pharmaceutical Sciences and All India Council for Technical Education (AICTE) for providing startup facilities to complete the study.

\section{REFERENCES}

[1] Balap, A., Lohidasan, S., Sinnathambi, A., Mahadik, K., Herb-Drug Interaction of Andrographis Paniculata (Nees) Extract and Andrographolide on Pharmacokinetic and Pharmacodynamic of Naproxen in Rats, J Ethnopharmacol, 1952017, 214-21.

[2] Perl, D.P., Neuropathology of Alzheimer's Disease, Mount Sinai Journal of Medicine: A Journal of Translational and Personalized Medicine, 77(1), 2010, 32-42.

[3] Martínez, A., Portero-Otin, M., Pamplona, R., Ferrer, I., Protein 
Targets of Oxidative Damage in

Human Neurodegenerative Diseases with Abnormal Protein Aggregates, Brain Pathol, 20(2), 2010, 281-97.

[4] Nunomura, A., Hofer, T., Moreira, P.I., Castellani, R.J., Smith, M.A., Perry, G., Rna Oxidation in Alzheimer Disease and Related Neurodegenerative Disorders, Acta Neuropathologica, 118(1),2009, 15166.

[5] Halliwell, B., Oxidative Stress and Neurodegeneration: Where Are We Now?, J Neurochem, 97(6), 2006, 1634-58.

[6] Ballatori, N., Krance, S.M., Notenboom, S., Shi, S., Tieu, K., Hammond, C.L., Glutathione Dysregulation and the Etiology and Progression of Human Diseases, Biol Chem, 390(3), 2009, 191-214.

[7] Kalmar, B., Greensmith, L., Induction of Heat Shock Proteins for Protection against Oxidative Stress, Adv Drug Deliv Rev, 61(4), 2009, 310-8.

[8] Ward, R.J., Zucca, F.A., Duyn, J.H., Crichton, R.R., Zecca, L., The Role of Iron in Brain Ageing and Neurodegenerative Disorders, The Lancet Neurology, 13(10), 2014, 1045 60.
[9] Arreguin, S., Nelson, P., Padway, S., Shirazi, M., Pierpont, C., Dopamine Complexes of Iron in the Etiology and Pathogenesis of Parkinson's Disease, J Inorg Biochem, 103(1), 2009, 87-93.

[10] Jellinger, K.A., Recent Advances in Our Understanding of Neurodegeneration, J Neural Transm (Vienna), 116(9), 2009, 1111-62.

[11] Skovronsky, D.M., Lee, V.M., Trojanowski, J.Q., Neurodegenerative Diseases: New Concepts of Pathogenesis and Their Therapeutic Implications, Annu Rev Pathol, 12006, 151-70.

[12] Palop, J.J., Chin, J., Mucke, L., A Network Dysfunction Perspective on Neurodegenerative Diseases, Nature, 443(7113), 2006, 768-73.

[13] Migliore, L., Coppedè, F., Genetics, Environmental Factors and the Emerging Role of Epigenetics in Neurodegenerative Diseases, Mutat Res, 667(1-2), 2009, 82-97.

[14] Israeli, E., Sharon, R., Beta-Synuclein Occurs in Vivo in Lipid-Associated Oligomers and Forms HeteroOligomers with Alpha-Synuclein, J Neurochem, 108(2), 2009, 465-74.

[15] Xia, W., Yang, T., Shankar, G., Smith, I.M., Shen, Y., Walsh, D.M., Selkoe, 
D.J., A Specific Enzyme-Linked Immunosorbent Assay for Measuring Beta-Amyloid Protein Oligomers in Human Plasma and Brain Tissue of Patients with Alzheimer Disease, Arch Neurol, 66(2), 2009, 190-9.

[16] Schwartz, A.L., Ciechanover, A., Targeting Proteins for Destruction by the Ubiquitin System: Implications for Human Pathobiology, Annu Rev Pharmacol Toxicol, 492009, 73-96.

[17] Muchowski, P.J., Wacker, J.L., Modulation of Neurodegeneration by Molecular Chaperones, Nat Rev Neurosci, 6(1), 2005, 11-22.

[18] Hartl, F.U., Hayer-Hartl, M., Converging Concepts of Protein Folding in Vitro and in Vivo, Nat Struct Mol Biol, 16(6), 2009, 574-81.

[19] Scheper, W., Hoozemans, J.J., Endoplasmic Reticulum Protein Quality Control in Neurodegenerative Disease: The Good, the Bad and the Therapy, Curr Med Chem, 16(5), 2009, 615-26.

[20] Eliezer, D., Biophysical Characterization of Intrinsically Disordered Proteins, Current Opinion in Structural Biology, 19(1), 2009, 2330.
[21] Desplats, P., Lee, H.J., Bae, E.J., Patrick, C., Rockenstein, E., Crews, L., Spencer, B., Masliah, E., Lee, S.J., Inclusion Formation and Neuronal Cell Death through Neuron-to-Neuron Transmission of Alpha-Synuclein, Proc Natl Acad Sci U S A, 106(31), 2009, 13010-5.

[22] Mendoza-Espinosa, P., GarcíaGonzález, V., Moreno, A., Castillo, R., Mas-Oliva, J., Disorder-to-Order Conformational Transitions in Protein Structure and Its Relationship to Disease, Mol Cell Biochem, 330(1-2), 2009, 105-20.

[23] Mecocci, P., Polidori, M.C., Antioxidant Clinical Trials in Mild Cognitive Impairment and Alzheimer's Disease, Biochimica et Biophysica Acta (BBA) - Molecular Basis of Disease, 1822(5), 2012, 631-38.

[24] Ellman, G.L., Tissue Sulfhydryl Groups, Arch Biochem Biophys, 82(1), 1959, 70-7.

[25] Green, L.C., Wagner, D.A., Glogowski, J., Skipper, P.L., Wishnok, J.S., Tannenbaum, S.R., Analysis of Nitrate, Nitrite, and [15n]Nitrate in Biological Fluids, Analytical biochemistry, 126(1), 1982, 131-8. 
[26] Ohkawa, H., Ohishi, N., Yagi, K., Assay for Lipid Peroxides in Animal Tissues by Thiobarbituric Acid Reaction, Analytical biochemistry, 95(2), 1979, 351-58.

[27] Lowry, O.H., Rosebrough, N.J., Farr, A.L., Randall, R.J., Protein Measurement with the Folin Phenol Reagent, J Biol Chem, 193(1),1951, 265-75.

[28] Roberts, A., Bill, B., Glanzman, D., Learning and Memory in Zebrafish Larvae, Frontiers in Neural Circuits, 7(126),2013.

[29] Mathur, P., Lau, B., Guo, S., Conditioned Place Preference Behavior in Zebrafish, Nature protocols, 6(3),2011, 338-45.

[30] Khatri, D., Juvekar, A., Abrogation of Locomotor Impairment in a RotenoneInduced Drosophila Melanogaster and Zebrafish Model of Parkinson's Disease by Ellagic Acid and Curcumin, International Journal of Nutrition, Pharmacology, Neurological Diseases, 6(2), 2016, 90-96.

[31] Reddy, P.H., Beal, M.F., Amyloid Beta, Mitochondrial Dysfunction and Synaptic Damage: Implications for Cognitive Decline in Aging and
Alzheimer's Disease, Trends Mol Med, 14(2), 2008, 45-53.

[32] Martin, H.L., Teismann, P., Glutathione - a Review on Its Role and Significance in Parkinson's Disease, The FASEB Journal, 23(10), 2009, 3263-72.

[33] Packer, L., Witt, E.H., Tritschler, H.J., Alpha-Lipoic Acid as a Biological Antioxidant, Free Radic Biol Med, 19(2), 1995, 227-50.

[34] Leimer, U., Lun, K., Romig, H., Walter, J., Grünberg, J., Brand, M., Haass, C., Zebrafish (Danio Rerio) Presenilin Promotes Aberrant Amyloid B-Peptide Production and Requires a Critical Aspartate Residue for Its Function in Amyloidogenesis, Biochemistry, 38(41),1999, 13602-09.

[35] Lieschke, G.J., Currie, P.D., Animal Models of Human Disease: Zebrafish Swim into View, Nat Rev Genet, 8(5), 2007, 353-67.

[36] Blaser, R., Gerlai, R., Behavioral Phenotyping in Zebrafish: Comparison of Three Behavioral Quantification Methods, Behavior Research Methods, 38(3), 2006, 456-69. 